\title{
EFFECTS OF ABSURDITY IN ADVERTISING: THE MODERATING ROLE OF PRODUCT CATEGORY ATTITUDE AND THE MEDIATING ROLE OF COGNITIVE RESPONSES.
}

\section{LEOPOLDO ARIAS-BOLZMANN}

Universidad Adolfo Ibáñez

\author{
GOUTAM CHAKRABORTY \\ Oklahoma State University
}

JOHN C. MOWEN

Oklahoma State University

This research was conducted as a part of the first author's dissertation at Oklahoma State University. We thank the members of the dissertation committee, Terry Bristol and Nancy Wilkinson, for their many helpful comments on this project. We thank Tim Heath for his comments on earlier versions of this manuscript. We also thank 
participants of the marketing department seminar held at the Nanyang Technological University, Singapore, for their helpful comments on this paper.

Las opiniones que se presentan en este documento son de exclusiva responsabilidad de sus autores y no reflejan necesariamente los puntos de vista de la Universidad Adolfo Ibáñez.

\title{
EFFECTS OF ABSURDITY IN ADVERTISING: THE MODERATING ROLE OF PRODUCT CATEGORY ATTITUDE AND THE MEDIATING ROLE OF COGNITIVE RESPONSES
}

\begin{abstract}
The presence or absence of an absurd image was manipulated in a simulated print advertisement for a fictitious brand of wine cooler. Consumers' prior attitude toward wine coolers was hypothesized to moderate the effectiveness of absurdity in advertising. Consumers' cognitive responses were hypothesized to mediate the impact of absurdity and prior product category attitude on consumers' attitude to the ad and brand.

The results support the moderating role of prior product category attitude. For subjects with negative prior attitude toward wine coolers, viewing the absurd ad resulted in a more positive attitude to the ad and brand than viewing the non-absurd ad. However, for subjects with positive prior attitude toward wine coolers, viewing the absurd ad did not result in any different ad or brand attitude than viewing the non-absurd ad. The results also support the
\end{abstract}


mediating role of cognitive responses. In addition, absurdity was found to impact brand name recall. 


\title{
EFFECTS OF ABSURDITY IN ADVERTISING: THE MODERATING ROLE OF PRODUCT CATEGORY ATTITUDE AND THE MEDIATING ROLE OF COGNITIVE RESPONSES.
}

\begin{abstract}
Absurd images frequently appear in advertisements (Stern 1990, 1992). In this paper we define absurd ads as incongruously juxtaposing pictorial images, words, and/or sounds that viewers perceive to be irrational, bizarre, illogical, and disordered. For example, ads for Camel cigarettes portrayed a dromedary, cigarette dangling from his mouth, participating in sports and wearing fashion clothing. Or, consider the British Airways ad in which dozens of shoes are shown flying into the sky. While no study has specifically counted the percentage of ads that use absurdity, some evidence of its prevalence is found in the Spring 1995 issue of Advertising Age. Fawcett (1995) identified the 50 best commercials appearing in the United States. Of these ads, nine can be clearly classified as absurd. Examples include the Energizer Bunny, Joe Isuzu, the Coca-Cola Polar Bears, and the California Raisins.
\end{abstract}

Despite the widespread use of absurdity in advertising by practitioners, until Stern's (1990) work, which related the absurdity construct to literature and drama, the topic had received little attention from academic researchers. The current study relates absurdity to traditional theories found in consumer behavior literature and then tests two competing approaches for understanding the effects of the construct. Specifically, we test competing predictions from the principle of evaluative consistency of cognitive elaborations (Tesser and Leone 1977, Chattopadhyay and Basu 1990) and from distraction theory (Festinger and Maccoby 1964, Petty, Wells, and Brock 1976, Petty and Cacioppo 1981). In addition to providing implications for theory, the results are relevant to advertising managers as well as public policy makers.

The paper will first discuss the construct of absurdity. After defining absurdity, the paper will link the construct to previous theoretical work in psychology and marketing on the impact of 
pictorial information on consumer responses. Results from an experiment will then be presented in which the presence or absence of an absurd image in a print ad was manipulated. After presenting the results of the study, the advertising and public policy implications of the research will be discussed.

\section{THEORETICAL FRAMEWORK}

\section{What Is Absurdity?}

Our definition of absurd ads is based upon an extensive literature review of the intellectual history, origins, and explanation of the concept of absurdity. Although space constraint prohibits us to report the entire literature review, we briefly describe below the major concepts from our review that forms the basis of our definition of absurdity. The concept of absurdity has roots going back to the field of philosophy in the early 1800s (writings of Soren Kierkegaard 1813-1855). It has since been discussed in the disciplines of art and literature. Artistic absurdity has its origins in 1916 when a group of refugee artists got together in Switzerland under the name of "Dada." The group insisted on artistic expression independent of rational control. According to Tristan Tzara (1957, p. 9), most of the plays that the "Dadaists" wrote and produced are essentially nonsense pieces and poems. By 1921, a new group sought order and methodology, and they reversed their revolt into a strict intellectual discipline (Richter 1965, p. 42). As a result, they converted to surrealism, which is associated with dream imagery, imaginative worlds, and physical distortions.

Absurdist literature, on the other hand, has its origins in absurdist philosophy. The crisis in modern thought, represented by Nietzsche, spawned the "absurdist movement." However, it was not until 1950 when Martin Esslin applied the word "absurd" in relation to literature. The "Theater of the Absurd" as defined by the critic, Martin Esslin (1969), is a significant style of dramatic writing in this century. Esslin (1969) also suggested that absurdity is the basis for 
the subtlest form of deceptiveness because it disrupts conventional notions about meaning by questioning its very existence. The term "absurdity" was coined to define a type of modern drama in which characters behave irrationally, where causal sequences of events are illogical, and where incongruous juxtapositions of people and things occur.

In marketing literature, Stern (1990) related the contemporary dramatic movement of "theater of the absurd" to marketing strategy. She discussed absurdity in terms of a standard dramatic framework consisting of theme, action, characters, language, setting, and tone. According to Stern (1990), drama literature shares an important common link with marketing literature: an author (the firm) communicates a text (the advertisement) to a reader (the consumer). She suggests a literary framework as an additional way of investigating marketing communication as drama. Thus, absurdity can be viewed as a literary form that advertising has adopted.

Today, the influence of absurdity extends to cinema and advertising (Kanner 1988). Some absurd advertisements create ambiguity by juxtaposing incongruous visual and verbal elements in sometimes humorous vignettes (Stern 1992). By its nature, absurdity can be humorous or perhaps even pernicious and sinister. Absurdity can emerge from many illogical relationships that may result from the use of surrealism, anthropomorphism, allegory, humor and hyperbole. Consequently, we view absurdity to be a general term under which a variety of more specific literary descriptors fall.

\section{Four Different Forms of Absurdity}

Absurdity may be communicated via surrealism, anthropomorphism, allegory, and hyperbole. Alcuaz (1984) proposed that surrealism is associated with dream imagery, imaginative worlds, and physical distortions. Surrealism is expressed by combining images in surprising ways. Surrealism tries to break every rule of photography and of editing so that final graphics become a visual surprise. Homer (1986) conducted an experiment investigating the effects of 
surrealistic design, involvement, and strength of message arguments on the effectiveness of print advertisements. Results indicated that the surreal ad with strong message arguments, under high involvement, induced the most effective information processing of the ad's content in terms of recall, recognition, attitudes, affect toward the ad, and behavioral intentions.

Another literary descriptor that falls within absurdity is anthropomorphism. Anthropomorphism is defined as an interpretation of what is not human or personal in terms of human or personal characteristics (Webster Dictionary). Although the literature on anthropomorphism is scant in the marketing field, in advertising we find frequent use of absurd images that enlist an anthropomorphic character to communicate meaning e.g., "Joe Camel."

A third literary descriptor that fits under absurdity's rubric is allegory. Allegory involves the description of something under the veiled pretense of something else (Stern 1990). For example, the popular California Raisin commercials represent an absurd allegory in which the qualities of liveliness, high spiritedness, and energy are represented by singing and dancing raisins. The common thread linking all allegory is a discontinuity of form. This is a dislocation that happens when reader expectations of a realistic narrative are jarred, and the narrative becomes a source of double meaning (Stern 1990).

Absurdity may also result from the use of humor and hyperbole. Humor is defined as something that is or is designed to be comical or amusing (Duncan and Nelson 1985). Humor can be present in advertising as a result of absurdity. However, an ad that employs humor may not be absurd, and an absurd ad does not necessarily have to be humorous. In marketing communications the use of a comic absurdist tone allows a firm to take itself lightly, admit to its flaws, and encourage the consumer to laugh along (Stern 1990). Hyperbole is a gross exaggeration used in order to make a point. Hyperbole is frequently used to create "absurd 
allegorical humor." Isuzu has taken this approach in its commercial where "lies" about their cars are presented in an entertaining way in order to demonstrate the car's real performance.

In summary, absurdity is a complex construct that may result from different types of illogical relationships such as the ones mentioned above. In this paper, we focus on absurdity that arises from illogical relationships among pictorial elements in an advertisement. Thus, we define absurdity as the incongruous juxtaposition of pictorial images that viewers perceive to be irrational, bizarre, illogical, and disordered. Just as there are many different types of message appeals (e.g., fear, humor, emotional etc.), there are also a variety of forms that absurdity may take. In this paper, we are investigating one particular type of absurdity -surrealism. 


\section{Theoretical Approaches for Predicting Effects of Absurdity}

We use two theoretical approaches from the psychology literature to understand the impact of absurdity in advertising. Our focus is on understanding when the use of absurdity in advertising is effective rather than whether absurdity enhances ad effectiveness. The former question seems more interesting because it seems unreasonable that absurd ads will be effective all the time. In many situations absurdity in advertisements may be clearly inappropriate. Therefore, we seek to develop a conceptual framework that explains how absurdity in ads influences consumers. Then, on the basis of this framework, we systematically examine the moderating role of variables such as audience characteristics to understand the conditions under which an absurd ad execution strategy may be appropriate.

\section{Absurdity in Ads and Consumers Information Processing}

We believe that there are at least two reasons why absurd ads are likely to be processed more extensively than non-absurd ads. First, the nature of absurd ads (incongruous juxtaposition of elements that consumers view as illogical, bizarre) suggests they are more likely to be noticed than non-absurd ads. Support for this line of reasoning comes from prior research about visual imagery mnemonics and surrealism. For example, O'Brien and Wolford (1982) suggested that bizarre images increase the distinctiveness of items. Rossiter and Percy (1987, p. 230) consider "bizarre executions" to be those characterized by visual gimmicks such as humor, trick photography, and innovative print layouts. One motivation for employing such executions, these authors argue, is to increase the probability that the ad will be noticed by consumers in an overpopulated information environment. Messaris (1997) argued that surrealism as practiced by artists such as Magritte or Dali was mainly an art of eye-grabbing visual paradoxes and continues to be used for the same purpose in today's ads. Finally, Arens (1999) also pointed out that absurdity is used in ads primarily to get a viewer's attention. We argue that noticing an ad is a necessary (but not sufficient) condition for the ad to be processed 
by consumers. Consequently, any phenomenon that increases the chance of noticing an ad will also increase the probability of its being processed by consumers.

Second, highly novel, unexpected stimuli (such as absurd ads) are thought to be processed more extensively. For instance, as described by Osgood (1964), von Restorff found that recall is enhanced when subjects are exposed to highly novel, unexpected stimuli. This von Restorff effect may apply to the development of novel advertising images, such as absurd images. Novel (unique) information acts to capture attention, making it more likely to be processed and later recalled than information that is redundant or expected to appear in a given context (Lynch and Srull 1982). Houston, Childers and Heckler (1987) found that pictorial information incongruent with prior expectations is more difficult to comprehend and stimulates more elaborate internal processing. The use of incongruous juxtaposition of visual elements in absurd ads suggests that the visual component of the absurd ad is to be likely incongruous with prior expectations of the audience. Hence, absurd ads may lead to more elaborate processing. Finally, prior research also suggests that enhanced attention typically leads to more extensive processing (Petty and Cacioppo 1985). Therefore, if absurd ads are more attention grabbing than non-absurd ads, the absurd ads may be processed more extensively. This effect of absurdity in ads is also consistent with the marketing literature that investigated the impact of pictorial stimuli in ads. Numerous studies have explored the role of pictures in advertising (Lutz and Lutz 1977, Edell and Staelin 1983, Heckler and Childers 1992). Many of these studies found that processing is enhanced in the presence of incongruent pictorial information. Because our definition of absurdity encompasses incongruity, we expect absurd ads to be processed more extensively than non-absurd ads.

\section{Absurdity in Ads and Product Category Attitude (PCA)}

We argue that to fully understand the effect of absurd versus non-absurd ads on consumers' responses, it is insufficient to know that absurd ads are processed more extensively; we also 
need to know the directionality of individuals' cognitive elaborations (Chattopadhyay and Alba 1988, Chattopadhyay and Basu 1990). The issue of evaluative directionality of individual responses is somewhat problematic for absurd ads because such ads are ambiguous and open to more idiosyncratic interpretation than non-absurd ads. Support for this contention comes from Stern (1992), who argued that the literary forms of absurdity (both visual and verbal) convey subjectively ambiguous meanings that can be interpreted differently by different consumers. This is particularly true for absurd ads employing visually rich images for which a message recipient may spontaneously generate idiosyncratic interpretation and elaboration because of the syntactic indeterminacy of visual images (Messaris 1997). Because absurd ads are more prone to idiosyncratic interpretation and elaboration, we expect that the more extensive processing of absurd ads will lead to greater attitude change only under conditions that bias the information processing in an evaluatively positive or negative direction.

\section{Effect of PCA as Predicted by the Principle of Evaluative Consistency}

A key determinant of the evaluative directionality of information processing is individuals' prior evaluation of the attitude object (Petty and Cacioppo 1981). Thus, consumers who are favorably predisposed to the product category are likely to be more receptive to and less critical of ads for that product category compared to consumers who are negatively predisposed toward the product category. Consequently, consumers who are favorably predisposed toward the product category, are more likely to generate evaluatively positive cognitive elaborations, which in turn will generate proportionately more positive cognitive responses, leading to more positive attitude to the ad and the brand. In contrast, those consumers who are negatively predisposed toward the product category are likely to be less receptive to and more critical of ads for that product. Therefore, their cognitive elaborations are likely to be evaluatively negative, which in turn will produce proportionately more 
negative cognitive responses, and result in more negative attitude to the ad and the brand. This moderating relationship is shown in Figure 1. 


\section{Figure 1}

\section{Consumer's Responses to Absurdism in Ads}

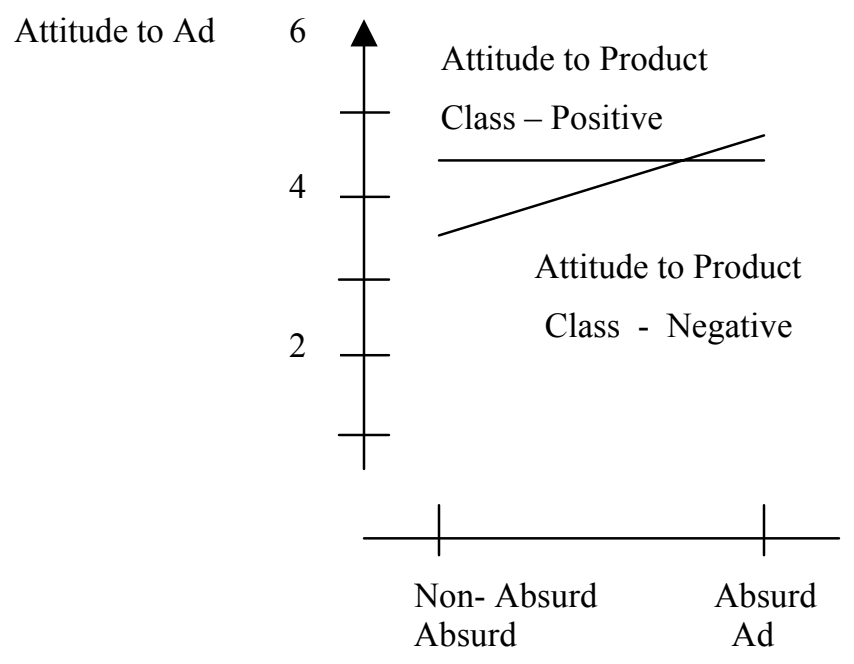

Attitude to Brand

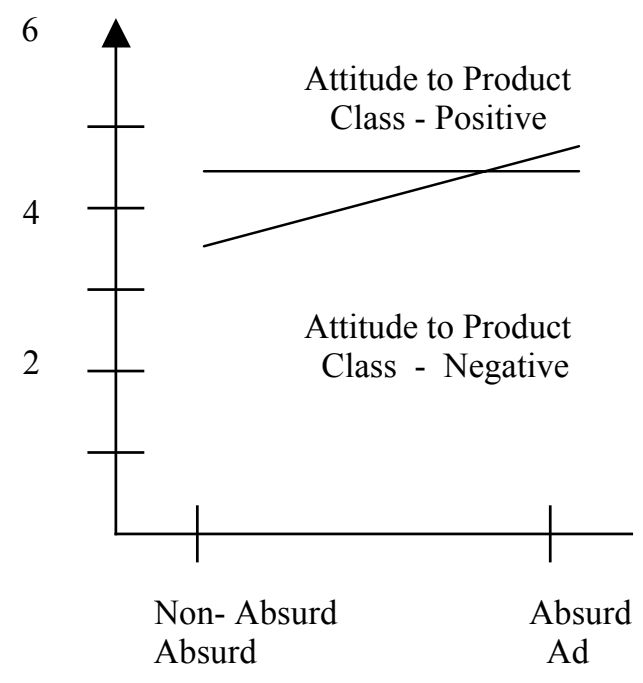

The ideas presented above are based on the evaluative consistency principle of cognitive elaborations (Tesser and Leone 1977). Chattopadhyay and Basu (1990) employed this principle to predict the effect of humorous versus non-humorous ads. The consistency 
principle suggests that for absurd ads, which are more ambiguous and open to idiosyncratic interpretations than non-absurd ads, the directionality or valence of an individual's prior attitude toward the product category will serve to bias the evaluative directionality of the individual's cognitive elaborations, and such biases will move in the direction of the prior evaluation. Therefore, when the message recipient's prior evaluation of a product category is favorable, we expect more positive persuasive effects from his or her exposure to an absurd ad. Conversely, absurd ads are likely to introduce a boomerang effect and lower persuasion when the message recipient has an unfavorable prior product category evaluation. In other words, consumers' product category attitude (from now on referred to as PCA) is expected to moderate the effect of absurdity in ads on consumers' responses.

\section{Effect of PCA as Predicted by the Distraction Theory}

This moderating role of PCA on the impact of absurdity in ads on consumers' responses is also supported by another theoretical mechanism. Festinger and Maccoby (1964), and Petty and Cacioppo (1981) investigated a theoretical mechanism by which nonverbal elements in an ad (e.g., absurd images in our study) may impact consumers' attitude. Festinger and Maccoby (1964) predicted that subjects who are negatively predisposed toward an advocated message, if they are distracted during the message presentation, would generate fewer counter arguments against the message. In turn, this would result in greater attitude change than if they were not distracted during the message presentation. Petty, Wells, and Brock (1976) extended the distraction hypothesis to include subjects who are favorably predisposed toward the advocated message. They predicted that any distraction during the message presentation would reduce the dominant cognitive responses. That is, subjects who are positively predisposed would generate fewer support arguments due to distraction, and subjects who are negatively predisposed would generate fewer counter arguments. Thus, for changing attitudes, distraction during message presentation would be beneficial for negatively predisposed subjects but detrimental for positively predisposed subjects. 
The distraction mechanism is, therefore, an alternative approach to explaining the impact of absurdity on attitude change if absurdity serves as a distraction agent. In social psychology as well as marketing literature, a typical manipulation of distraction involves subjects' being asked to participate in rather strange and unrelated tasks while simultaneously being exposed to persuasive communication (Bither 1972, Festinger and Macoby 1964, Gardner 1970). Nelson, Duncan, and Frontczak (1985) criticized such extreme and unrelated manipulations of distraction and argued that elements of an ad such as humor may also serve as a distraction agent during information processing. We contend that just as humor in an ad may distract subjects from processing the message, so too can absurdity distract subjects' processing of the message in an ad.

Notice, however, that although the distraction mechanism is used to predict a moderating role of PCA, the pattern of this moderation is different from that predicted by consistency of evaluative principles. Specifically, based on the role of absurdity as a distraction agent during processing, it is predicted that when subjects are positively predisposed toward the product class, absurdity will reduce the number of support arguments (positive cognitive responses) resulting in a less positive attitude. On the other hand, when subjects are negatively predisposed toward the product class, absurdity will reduce the number of counter arguments (negative cognitive responses) resulting in a less negative attitude.

Thus, both theoretical mechanisms (evaluative consistency principle and distraction) predict an interaction between consumers' PCA and the presence or absence of an absurd ad on consumers' responses. However, the predicted patterns of the interaction from the two theories are very different. Although we could have set up hypotheses for a specific pattern based on any one theory, in this paper we are taking a comparative approach rather than a confirmatory approach to theory testing (Sternthal, Tybout, and Calder 1987). That is, rather than trying to confirm or disconfirm predictions from any one theory, we are trying to 
empirically demonstrate the superiority of one explanation over its rivals. Based on the above discussion, the following hypothesis is predicted:

H1: Consumers' product category attitude (PCA) will moderate the impact of (i.e., interact with) absurdity in ads on consumers' attitudes toward the ad and brand.

\section{Absurdity in Ads and Process Measures (Cognitive Responses)}

The discussion of the processes underlying the moderating role of prior product category evaluation on the impact of absurd ads on consumers' attitude toward ad and brand suggests that cognitive responses lie at the heart of this moderating (interaction) effect. Both theories predict that cognitive responses will mediate the interaction effect of PCA and absurdity on consumers' attitudes to ad and brand (as shown in Figure 1). That is, absurdity and PCA first jointly influence cognitive responses, which in turn impact consumers attitudes to ad and brand. However, whether consumers with positive PCA will generate proportionately more (less) positive cognitive responses leading to more (less) positive attitudes to ad and brand depends on the theory -- evaluative consistency (distraction). Similarly, whether consumers with negative PCA will generate proportionately more (less) negative cognitive responses leading to more (less) negative attitudes to ad and brand also depends on the theory --

evaluative consistency (distraction). Based on our previously stated intention to do a comparative approach to theory testing, we only hypothesize the mediating effect of cognitive responses without specifying its pattern.

H2: Cognitive responses will mediate the joint (interaction) effect of PCA and absurdity in ads on consumers' attitudes toward the ad and brand.

\section{Absurdity in Ads and Recall}


Our focus in this paper is on the effect of absurdity on attitudinal measures. However, for obvious reasons, marketers are often interested in brand name recall (learning) measures beyond attitudinal measures of persuasion. There is also some theoretical interest to explore how consumers' recall of brand name information from an ad is influenced by absurdity in ads because of conflicting patterns of results for recall reported in prior studies. For example, Osterhouse and Brock (1970) reported no effect of distraction on recall, Haaland and Venkatesan (1968) showed reduced recall due to distraction, and Houston, Childers, and Heckler (1986) demonstrated enhanced recall for schema discrepant information. Therefore, we plan to empirically test the pattern of brand name recall across our experimental conditions. 


\section{METHOD}

\section{Overview}

An experimental approach was taken in which print ads for a fictitious wine cooler were created. Two versions of a base ad were developed -- one of which was absurd. All ads contained a standard warning about the negative health effects of consuming alcohol. In the main experiment, a two factor $(2 \times 2)$ between-subjects experimental design was employed. The first factor was whether subjects viewed an absurd or a non-absurd image in a print advertisement. The second factor consisted of the directionality of subjects' prior attitude toward the product category (i.e., positive or negative attitude) which was measured several weeks before the main experiment under the pretense of a different study.

A number of pretests were conducted employing subjects from the same population used in the main experiment. However, care was taken to ensure that none of the subjects who participated in the pretests also participated in the main experiment. These pretests helped us to (1) assess the relevance of our product to the subjects, (2) ensure that both versions (absurd and non-absurd) of the ad were perceived to be professionally produced and to contain the same information, and (3) check that subjects understood the instructions and scales used in the study. The results from these pretests are briefly discussed below. Interested readers may acquire more details from the first author.

\section{Selection of Product}

The choice of a suitable product was guided by our desire to minimize the impact of potential confounding factors while selecting a product for which subjects' attitude exhibited a reasonable variance for both males and females and for which the difference in attitude between genders was minimal. In the first pretest, 80 undergraduate students (61 percent 
females and 39 percent males) from a large midwestern university were asked to rate seven alcoholic drink products using a scale ranging from zero to one-hundred in intervals of ten with end-anchors as " $0=\mathrm{I}$ dislike very much" and "100 = I love it." Of the seven alcoholic products, wine coolers were found to best fit this requirement (mean and s.d. of attitude were 35.7 and 27.6 for males and 51.2 and 32.8 for females). Thus, a wine cooler (a product with moderate levels of attractiveness and reasonable variance across both males and females) was selected as the experimental stimulus.

\section{Stimuli Construction}

The critical variable to be manipulated in the study was absurdity. The goal of the manipulation was to induce absurdity by rearranging (with minimal changes) elements of the ad. We started with a pool of twenty wine cooler ads with absurd themes developed by students in a graphic design class. These twenty ads were extensively pretested with experts and consumers in two different focus groups. Based on these pretests, one of the twenty ads was chosen and professionally recreated. The selected ad employed a pictorial image in which a woman was emerging from the ocean with a wine cooler in her hand and a volcano "sitting like a hat" on her head. The juxtaposition of the two different sized objects was incongruous, bizarre, and irrational. An important condition for selection of this image was that when the volcano was removed from her head and placed in the background, the absurdity was

eliminated while the same fundamental pictorial and written information in the ad was retained (the non-absurd condition). To avoid the confounding effect of prior brand attitude, we used a fictitious brand of wine cooler named "Caribbean Cooler." The brand name and the slogan were also chosen based on pretests. The final versions of the ads were produced in a professional 4-color format (see Appendix).

\section{Procedure}


One hundred and seventy-eight undergraduate students participated in the main experiment and received extra credit in their marketing classes. Several weeks prior to the beginning of the main experiment, students' attitudes toward wine coolers (PCA) were measured by using a seven-item 9-point semantic differential scale (Osgood, Suci, and Tannenbaum 1957) under the pretense of a different study. An attitude index was formed by averaging the seven-item semantic differential scale items (Cronbach's alpha $=0.96$ ). Subjects' product category attitudes were classified as negative or positive depending on whether their score was lower than the 33rd percentile (scale score $=3.6$ ) or higher than the 66th percentile (scale score $=$ 5.8). Because our theoretical framework makes specific predictions for subjects with positive or negative PCA, all subsequent data analysis (except scale reliabilities) are conducted by using only subjects from those two groups. In other words, subjects whose scores fell in the middle third of the distribution of PCA scores were not included in order to create maximum difference between the positive and negative PCA groups. We note that a similar procedure has been followed before by Inman, McAlister and Hoyer (1990) and Petty and Cacioppo (1986). This resulted in a final sample size of one hundred twenty-one (cell sizes varied from 27 to 34$)$.

The main experiment was conducted with groups of six to eight students in a small conference room. Upon arrival, subjects were asked to read a cover story describing the experiment as a "pretest about an advertising campaign." The cover story stated that the study was for an advertising firm that wanted to obtain consumers' overall impressions about a number of ads. It was explained that such pretests were conducted commonly in the industry. After reading the cover story, subjects were exposed to four ads projected for twenty seconds each onto a screen via a slide projector. Pre-tests revealed that subjects took from 7.55 to 20.05 seconds to view the different versions of the ad. Thus, 20 seconds was considered adequate for this task. The target ad was always located in the third position. After exposure to all four ads, subjects were given two minutes to write down everything they could remember about the wine cooler ad (during an earlier pretest, two minutes proved sufficient for this task). After 
the unaided recall, they were asked to write down "all thoughts that you can remember going through your mind while you were looking at the wine cooler advertisement." They then answered a battery of questions about the wine cooler ad and the brand. In addition, they responded to scales that measured their mood and task involvement as well as the humor and absurdity in the ad. These scales were followed by questions about subjects' demographics and thoughts concerning the purpose of the experiment. At the end of the session, subjects were thanked and completely debriefed.

\section{Operationalization of Dependent Variables}

Four dependent measures were used in this study: attitude to ad, attitude to brand, brand name recall, and cognitive responses. Subjects' attitudes toward the ad were measured using Holbrook and Batra's (1987) four-item index (dislike-like, unfavorable-favorable, negativepositive, and bad-good). Subjects' attitudes toward the brand were assessed via seven-point semantic differential scales. The bipolar adjectives in this scale included the four (pleasantunpleasant, agreeable-disagreeable, satisfactory-unsatisfactory, and positive-negative) suggested by Osgood, Suci, and Tannenbaum (1957) plus six others (tastes good-tastes bad, exciting-dull, romantic-unromantic, weak-powerful, social-not social, and expensiveinexpensive).

To measure the unaided recall of the brand name, subjects' written comments were coded and analyzed by two judges to determine whether subjects mentioned the term "Caribbean Cooler." For cognitive responses, the same two judges coded and analyzed subjects' thoughts. Both judges were unaware of the experimental manipulations. All differences in coding between the two judges were resolved through discussion between the two judges. As

mentioned earlier, the ad contained little information about the brand. Therefore, in coding the cognitive responses, ad and brand-related thoughts were not separated. A cognitive response score was calculated for each subject as proportion of positive cognitive responses 
(the number of positive responses divided by the sum of positive and negative responses). The choice of using the positive response in the numerator of this index is arbitrary. However, the results would remain the same if we recast our hypotheses in terms of negative responses and test those using an index for proportion of negative responses.

\section{RESULTS}

\section{Reliability of Various Measures}

Whenever possible, multiple measures and previously published scales (with modifications as required) were used to measure each variable employed in the study. Table 1 presents the reliability indices and the Cronbach's alphas for each scale. From the table, it can be seen that high internal consistencies were obtained for all scales (all alphas were greater than 0.80). For recall and cognitive response measures, reliability indices were calculated for the two judges based on the formula developed by Perreault and Leigh (1989). All reliability indices were acceptable.

\section{Table 1}

\section{Cronbach's Alpha and Reliability Indexes}

\begin{tabular}{|l|c|c|}
\hline \multicolumn{1}{|c|}{ Scale/Measure } & Cronbach's Alpha & Reliability Index \\
\hline Attitude Toward the Ad & 0.95 & N/A \\
\hline Attitude Toward the Brand & 0.94 & N/A \\
\hline Absurdity & 0.86 & N/A \\
\hline Product Category Attitude (PCA) & 0.96 & N/A \\
\hline Brand Name Recall & N/A & 0.94 \\
\hline Positive Cognitive Responses & N/A & 0.77 \\
\hline Negative Cognitive Responses & N/A & 0.84 \\
\hline
\end{tabular}

\section{Manipulation Checks}


We developed a seven-item 7-point Likert scale to measure the manipulation of absurdity. The five items of absurdity (irrational, confusing, festive, menacing, and bizarre) reported in Arias-Bolzmann and Mowen (1992) were expanded by nine additional items (unique, unusual, unexpected, illogical, absurd, comical, unreal, disordered, cannot happen in real life ) based on our review of the absurdity literature. This 14-item scale was pretested with 60 undergraduate students. Based on item-to-total correlation and Cronbach's alpha, the 14 items were reduced to seven items. These seven items of the absurdity scale (bizarre, unique, unusual, illogical, absurd, comical, and unreal) were averaged to create an index (coefficient alpha $=0.86$ ). ANOVA with this index as the dependent variable and the type of ad, prior attitude, and the 2way interaction as independent variables revealed the only statistically significant effect to be the main effect for the type of ad $(F=31.99, p<.01)$. The mean responses were in the expected direction (4.86 for absurd ads versus 3.35 for non-absurd ads, with higher numbers representing more absurdity).

\section{Analysis of Attitude to the Ad and Brand}

In this study, subjects had no opportunity to get brand information other than what was mentioned in the ad. However, the ads contained little brand information. Thus, there is a very high correlation (0.89) between attitude to the ad and attitude to the brand. The analysis of variance results are therefore very similar for attitude to the ad and attitude to the brand. Therefore, in the interest of conserving space, we are only discussing results from the attitude to the ad analysis.

We predicted an interaction between absurdity and PCA in $\mathrm{H}_{1}$. This interaction (along with the main effect of PCA) was found to be statistically significant as shown in Table 2. Recall that the interaction (or moderating effect) was predicted by both theoretical mechanisms -evaluative consistency principle and distraction. However, the two theories differed on the 
expected pattern of means characterizing the interaction. The principle of evaluative consistency suggested that for subjects who have positive (negative) attitude toward wine coolers, exposure to an absurd ad will result in more positive (negative) attitude to the ad than exposure to a non-absurd ad. However, distraction mechanism suggested that for subjects who have positive (negative) attitude toward wine coolers, exposure to an absurd ad will result in less positive (negative) attitude to the ad than exposure to a non-absurd ad.

The means for interpreting the significant interaction are shown graphically in Figure 2 . The patterns of means are more supportive of the distraction hypothesis than the principle of evaluative consistency of cognitive elaborations. Follow-up tests for simple effects of absurdity at each level of PCA were conducted to test the patterns in Figure 1. For subjects with negative PCA, the average attitude to the ad was significantly higher following subjects' exposure to the absurd ad than the non-absurd ad (absurd ad mean $=4.39$, non-absurd ad mean $=3.30, \mathrm{~F}(1,117)=5.65$, $\mathrm{p}$-value $=0.02$ ). However, for those with positive PCA, there was no significant difference in subjects' attitude toward ad following exposure to an absurd or a nonabsurd ad (absurd ad mean $=4.55$, non-absurd ad mean $=4.85, \mathrm{~F}(1,117)=0.43$, $\mathrm{p}$-value $=$ 0.52). Thus, there is strong support of the pattern predicted by distraction hypothesis for subjects with negative PCA. However, for subjects with positive PCA, results only show directional support of the pattern predicted by the distraction hypothesis. 
Table 2

ANOVA Results for Consumers'Responses

Dependent Variable: Attitude toward the Ad

\begin{tabular}{|l|c|c|c|c|c|}
\hline \multicolumn{1}{|c|}{ EFFECT } & SS & df & F-stat & p-value & $\begin{array}{c}\text { Effect } \\
\text { Size (Eta) }\end{array}$ \\
\hline $\begin{array}{l}\text { Product Category Attitude } \\
\text { (PCA) }\end{array}$ & 21.27 & 1 & 6.72 & 0.01 & 0.23 \\
\hline Absurdity(Ad) & 4.67 & 1 & 1.48 & 0.23 & 0.11 \\
\hline Ad*PCA & 14.56 & 1 & 4.60 & 0.03 & 0.19 \\
\hline Error & 370.14 & 117 & & & \\
\hline
\end{tabular}

Dependent Variable: Attitude Toward the Brand

\begin{tabular}{|l|c|c|c|c|c|}
\hline \multicolumn{1}{|c|}{ EFFECT } & SS & df & F-stat & p-value & $\begin{array}{c}\text { Effect } \\
\text { Size (Eta) }\end{array}$ \\
\hline $\begin{array}{l}\text { Product Category Attitude } \\
\text { (PCA) }\end{array}$ & 17.92 & 1 & 8.40 & 0.01 & 0.26 \\
\hline Absurdity(Ad) & 4.57 & 1 & 2.15 & 0.15 & 0.13 \\
\hline Ad*PCA & 8.11 & 1 & 3.81 & 0.05 & 0.18 \\
\hline Error & 249.50 & 117 & & & \\
\hline
\end{tabular}

Dependent Variable: Proportion of Positive Cognitive Responses

\begin{tabular}{|l|c|c|c|c|c|}
\hline \multicolumn{1}{|c|}{ EFFECT } & SS & df & F-stat & p-value & $\begin{array}{c}\text { Effect } \\
\text { Size (Eta) }\end{array}$ \\
\hline $\begin{array}{l}\text { Product Category Attitude } \\
\text { (PCA) }\end{array}$ & 3.47 & 1 & 8.40 & 0.01 & 0.42 \\
\hline Absurdity(Ad) & 0.40 & 1 & 2.74 & 0.10 & 0.16 \\
\hline Ad*PCA & 0.64 & 1 & 4.39 & 0.04 & 0.20 \\
\hline Error & 15.84 & 109 & & & \\
\hline
\end{tabular}


Figure 2

\section{Cognitive Responses to Absurdism in Ads}

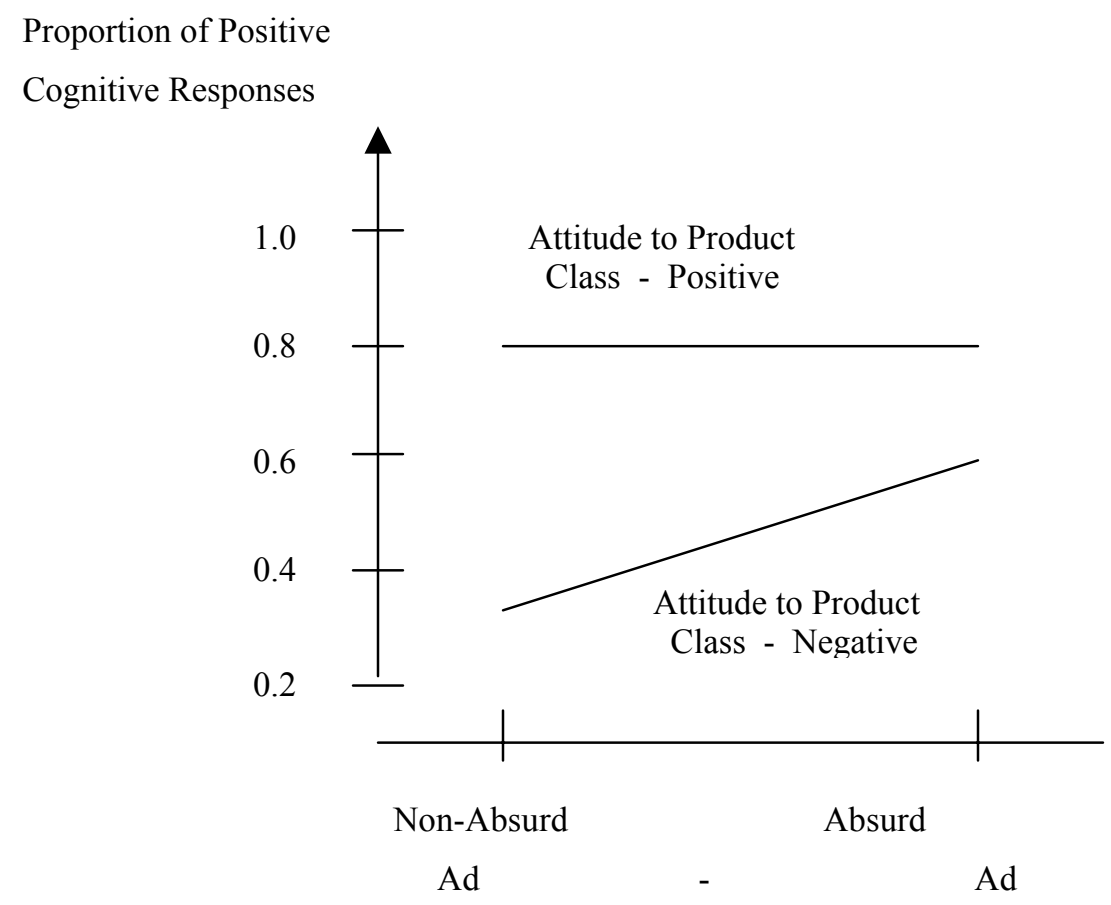

\section{Analysis of Cognitive Responses}

Both the distraction and consistency of evaluative principle theories predicted an interaction between PCA and absurdity on proportion of positive cognitive responses. Based on the principle of evaluative consistency of cognitive elaborations, we predicted that subjects with positive (negative) PCA would generate proportionately more (less) positive responses in the absurd ad condition compared to the subjects in the non-absurd ad condition. However, based on the distraction theory, we predicted that subjects with positive (negative) PCA would generate proportionately less (more) positive responses in the absurd ad condition compared to the subjects in the non-absurd ad condition. 
The ANOVA results reported in Table 3 support the prediction of the interaction. The pattern of the interaction shown in Figure 2 is again more supportive of the predictions based on the distraction mechanism. Specifically, subjects with negative PCA generated proportionately more positive cognitive responses after watching the absurd versus the non-absurd ad (absurd ad proportion $=0.58$, non-absurd ad proportion $=0.31, \mathrm{~F}(1,109)=7.04$, p-value $=0.01)$. However, subjects with positive PCA generated about the same proportion of positive cognitive responses whether they watched the absurd or the non-absurd ad (absurd ad proportion $=0.78$, non-absurd ad proportion $=0.81, \mathrm{~F}(1,109)=0.09, \mathrm{p}$-value $=0.76)$. Thus, the proportion of positive cognitive responses analysis also strongly supports the pattern predicted by the distraction hypothesis for subjects with negative PCA. However, as in the case of attitude to ad, the result of cognitive responses is only directionally consistent with predictions from the distraction hypothesis for subjects with positive PCA.

\section{Cognitive Responses as Mediators}

Our discussion of the mechanism of how absurdity and PCA impact consumers' attitude to the ad suggests that cognitive responses play a mediating role. This mediating role of cognitive responses was predicted in $\mathrm{H}_{2}$ by both theories -- evaluative consistency and distraction. According to Barron and Kenny (1986), three conditions need to be met to classify a variable as a mediator. These conditions are: (1) independent variables significantly account for variation in the mediator, (2) variations in the mediator account for variation in the dependent variable, and (3) when the variance accounted for by the mediator is partialed out of the variance in the dependent variable, the previously significant relationship between the independent and dependent variable no longer remains significant.

The ANOVA results reported in Table 2 satisfy the first condition. That is, we have already established a significant relation between independent variables (ad type and PCA) with the mediator (cognitive responses). To check for the other two conditions, we reanalyzed the attitude to the ad and the brand using the proportion of cognitive responses as a covariate. The 
results reported in Table 3 clearly support the mediating role of cognitive responses. The effect of the mediator (cognitive responses) on the dependent variable (ad attitude) is significant (satisfies the second condition), and the previously significant main and interaction effects of the independent variables (ad type and PCA) are no longer significant (satisfies the third condition). In other words, once shared variance between ad attitude and cognitive responses was partialed out, there are no residual effects of the independent variables (ad type and PCA) on the dependent variable (ad attitude). This suggests that the independent variables impact the dependent variable solely through the mediating variable (i.e., cognitive response is playing a full mediating role) as predicted in $\mathrm{H}_{2}$.

Table 3

\section{ANCOVA Results for Mediating Role of Cognitive Responses}

\section{Dependent Variable: Attitude Toward the Ad}

\begin{tabular}{|l|c|c|c|c|}
\hline \multicolumn{1}{|c|}{ EFFECT } & SS & Df & F-stat & p-value \\
\hline $\begin{array}{l}\text { Proportion of Positive } \\
\text { Cognitive Responses }\end{array}$ & 254.25 & 1 & 202.47 & 0.00 \\
\hline $\begin{array}{l}\text { Product Category Attitude } \\
\text { (PCA) }\end{array}$ & 3.36 & 1 & 2.68 & 0.11 \\
\hline Absurdity (Ad) & 0.00 & 1 & 0.00 & 0.97 \\
\hline Ad*PCA & 1.29 & 1 & 1.03 & 0.31 \\
\hline Error & 135.62 & 108 & & \\
\hline
\end{tabular}

Dependent Variable: Attitude Toward the Brand

\begin{tabular}{|l|c|c|c|c|}
\hline \multicolumn{1}{|c|}{ EFFECT } & SS & Df & F-stat & p-value \\
\hline $\begin{array}{l}\text { Proportion of Positive } \\
\text { Cognitive Responses }\end{array}$ & 151.12 & 1 & 149.94 & 0.00 \\
\hline $\begin{array}{l}\text { Product Category Attitude } \\
\text { (PCA) }\end{array}$ & 0.31 & 1 & 0.31 & 0.58 \\
\hline Absurdity (Ad) & 0.17 & 1 & 0.17 & 0.69 \\
\hline Ad*PCA & 0.92 & 1 & 1.92 & 0.34 \\
\hline Error & 108.85 & 108 & & \\
\hline
\end{tabular}


Note: In the ANCOVA models reported above, only the "Proportion of Positive Cognitive Responses" variable is used as a covariate.

\section{Analysis of Brand Name Recall Data}

As stated earlier, because of managerial and theoretical interests, we wanted to examine the impact of absurdity in an ad on consumers' recall of brand name. Brand name recall was operationalized as a dichotomous variable and coded as 1 if recalled, 0 otherwise. This variable was analyzed using logistic regression with type of ad, PCA, and the interaction between the two as predictor variables. The analysis reveals significant ( $p$-value 0.01) main effects for ad type and PCA and a significant (p-value $<0.01$ ) interaction effect between ad type and PCA. Examinations of relevant cell frequencies indicate that for subjects with negative PCA, brand name recall was significantly higher in the absurd ad condition (56.7\%) than the non-absurd ad $(10 \%)$ condition $(\mathrm{t}(58)=4.34$, $\mathrm{p}$-value $<0.01)$. However, subjects with positive PCA were somewhat less likely to recall the brand name in the absurd ad $(29.4 \%)$ than the non-absurd ad $(51.9 \%)$ condition $(\mathrm{t}(59)=1.80$, p-value $<0.08)$. The pattern of brand name recall for negative PCA groups was identical to the pattern of persuasion measures such as attitude to ad and brand. However, compared to persuasion measures, the pattern of brand name recall for positive PCA groups showed a clearer distraction effect.

\section{DISCUSSION}

Our results revealed that introducing absurdity into print advertisements has a complex set of effects on consumers' cognitive responses, attitude to the ad and brand, and brand name recall. As predicted in $\mathrm{H}_{1}$, absurdity together with subjects' prior attitude toward the product class influenced subjects' attitude to the ad and brand. This effect of absurdity was clearly evident 
for subjects with negative prior attitude toward the product class. For subjects who were negatively predisposed toward the product class, absurd ads resulted in proportionately more positive cognitive responses and consequently more positive attitude to the ad and the brand than non-absurd ads. However, for subjects who were positively predisposed toward the product category, absurd ads did not generate proportionately more positive cognitive responses and were not any more effective than non-absurd ads in influencing subjects' attitude to the ad or the brand. The pattern of the results was more consistent with predictions from distraction hypothesis than predictions from evaluative consistency of cognitive elaborations. Also, as predicted in $\mathrm{H}_{2}$, cognitive responses mediated the effect of absurdity and PCA on consumers' attitude towards the ad and brand.

Absurdity in ads enhanced subjects' recall of the brand name, particularly for those who were negatively predisposed toward the product class. However, for subjects positively predisposed to the product class, absurdity in an ad reduced brand name recall. Overall, absurdity in an ad increased recall of brand name. This pattern of result for brand name recall is similar to the pattern of results we observed for persuasion measures (attitude to ad and brand). We note however that for subjects positively predisposed to the product class, the distraction effect was more transparent in the brand name recall data than in the persuasion measures data.

\section{Implications of Our Results}

If supported by future research, we believe that our exploratory results have important theoretical and managerial implications. For academicians, our research begins the process of linking absurdity to other theoretical models in consumer research. Developing such theoretical linkages are important for bridging the gap of knowledge that currently exists between practitioners (as evidenced by widespread use of absurdity in ads) and academicians (as evidenced by the lack of empirical research on absurdity). 
The findings broaden our understanding of the effects of absurdity in ads in several ways. First, we argued that it is necessary to adopt a theory-driven contingency view of the impact of advertising. Our results highlight the benefits of such an approach in providing directions for future research. Second, our use of comparative approach to testing theory-driven predictions recognizes that theory tests provide a basis for judging rather than for proving theories. Viewed from this perspective, we find that the distraction mechanism provides a superior explanation of efficacy of absurdity than the principle of consistency of elaborations.

For marketers our results showed that absurdity in most instances had a positive influence on advertising effectiveness as measured by brand name recall, attitude to the ad and brand. More importantly, absurdity seems to be especially effective for those consumers who have a prior negative attitude toward the product class. This effect could be particularly important in ads seen by non-users of a product category. Initially, non-users of a product category may have negative attitude toward a product. Over time, exposure to absurd ads could impact their evaluations of the advertised brand. Our study results also have implications for creative directors. We believe our conceptualization and definition of absurdity will help creative directors develop absurd ads. However, our results also indicate that absurd elements in ads need careful testing. Perhaps, our absurdity scale along with other traditional measures (such as believability, likeability, etc.) should be used for testing such ads.

\section{Limitations and Future Research Directions}

Our study suffers from the generic limitations of all laboratory studies with forced exposure to ads in that the external validity is sacrificed at the cost of the internal validity. It is possible that under natural viewing conditions, consumers will only choose to expose themselves to ads

for product categories of their choice, and thus the observed enhancing effects of absurdity (especially for consumers with negative PCA) may not materialize. We attempted to control for some of these issues by measuring consumers' task involvement, need for cognition, mood 
etc. However, these control variables had low correlations $(<0.16)$ with dependent variables and therefore were not useful as covariates.

A related issue involves the generalizability of our research findings across products, mediums, and subject populations. This study is limited to only one product type and one medium (print ad). Future studies should, therefore, employ a variety of product types and different mediums (TV) to investigate if the findings generalize to diverse conditions. Additionally, our use of student subjects (some of whom may have been underage and or nondrinkers of alcoholic products) is also a limitation of this research. As one of the reviewers pointed out, alcoholic beverage advertisers do not test their ads with underage subjects or nondrinkers. Hence future research should investigate whether observed results will hold if subjects are sampled from a population of alcoholic beverage drinkers.

Another limitation is the degree of absurdity achieved in our manipulation. We consider the difference in the degree of absurdity between our absurd and non-absurd ads as medium. Future research should explore whether more extreme differences in the degree of absurdity between absurd versus non-absurd ads will produce different results compared to our study. We speculate that the degree of absurdity achieved in our manipulation is a possible cause of the flat findings for the group of subjects with positive PCA. In other words, the absurdity in our test ad is of a medium degree, which may have been sufficient to produce the expected effect (based on distraction theory) on subjects with negative PCA. However, for subjects with positive PCA, to produce the expected effect (based on distraction theory) we probably needed a stronger degree of absurdity manipulation.

Our use of a fictitious brand and minimal brand information in the ads may have resulted in identical pattern of effects of absurdity on consumers' attitude to ad and brand. Also, the mediating effect of cognitive responses supported by our data is limited due to our choice of not distinguishing between ad and brand related thoughts. It is possible that future research 
(using extant brands or with more brand information in ads) may find that the ad-related cognitive responses will mediate the effect of absurdity on ad attitudes only. However, absurdity's impact on brand attitudes may be mediated by both brand-related cognitive responses and ad attitudes. Similar limitations of our study arise from our chosen operationalization of product category attitude (i.e., ignoring the neutral or middle group), and coding of only brand name recall (i.e., ignoring recall of other elements such as visual material, message etc.) from the ad. Again, these issues should be investigated in future research.

Another related set of limitations stems from our lack of measurement of certain issues. For instance, we have measured the directionality (valence) of prior product category attitude (PCA) using a semantic differential type scale. However, we have no direct measures of belief strength of product category attitude. As pointed out by one of the reviewers, it is possible that belief strength may have played a role in the difference in results observed for positive versus negative PCA groups. Additionally, we do not have direct measures of distraction during message presentation, and this is also a limitation of our study.

Future research could also investigate effects of other individual characteristics, such as prior knowledge, on consumer information processing when exposed to absurd ads. Many researchers have demonstrated the differences in processing between high and low knowledge individuals (Johnson and Russo 1984, Sujan 1985). For ambiguous stimuli such as absurd ads, the differences may be even more pronounced between high and low knowledge consumers (Herr 1989). Another avenue for future research would be to examine the effect of absurdity by manipulating the cognitive context in which the judgments are made (Herr, Sherman, and Fazio 1983). For instance, due to the ambiguous nature of absurd ads, it is likely that if subjects are first unobtrusively primed with exemplars from product category, their subsequent evaluations of ad and brand may show either assimilation or contrast effects 
depending on the nature of the exemplar (extreme versus moderate) and the type of ad (absurd or non-absurd).

Another area of future research involves investigating the absurdity scale. Although our scale items are internally consistent and have face validity, we have no evidence of convergent or discriminant validity of this scale, and these validity issues need to be explored in future research.

A final area of future research involves investigating other forms of absurdity. In order to minimize confounds, we focused on a manipulation of pictorial elements in an ad to create absurdity. Thus, the woman with a volcano on her head in our ad represents a surrealistic image. It is possible to create absurdity by manipulating the copy elements (e.g., using hyperbole), or by employing anthropomorphic images. These alternative approaches are worthy of future studies.

\section{CONCLUSION}

Like all investigations of communication effects, our manipulation of absurdity is just one variation (surrealism) of many possible means of varying the construct. Future research should therefore investigate absurd ads created using other forms of illogical relationships such as allegory, anthropomorphism, hyperbole etc. We have some preliminary evidence (using one study) that distraction theory may provide a better explanation of effect of absurdity than evaluative principle of cognitive elaborations. Clearly, more research is needed before concluding the superiority of one theory over the another. In addition, given the complex nature and possible multi-dimensionality of the absurdity construct, future research in construct validation would be a high priority. We hope our study will stimulate more future research on this important but under-researched construct. 
APPENDIX 


\section{REFERENCES}

Alcuaz, Marie de (1984), "Contemporary Idioms of Surrealism," Dreamworks, Vol. 4, No. 1, 59-69.

Anderson, John and Gordon Bower (1980), Human Associative Memory. Hillsdale, NJ: Lawrence Erlbaum.

Arens, Williams F. (1999), Contemporary Advertising, Boston: Irwin McGraw-Hill.

Arias-Bolzmann, Leopoldo and John C. Mowen (1992), "Absurd Images in Cigarette Advertising: An Empirical Investigation," in Marketing: Perspectives for the 1990s, Robert L. King, ed., Southern Marketing Association, (Proceedings) 295-299.

Barron, Reuben M. and David A. Kenny (1986), "The Moderator-Mediator Variable Distinction in Social Psychological Research: Conceptual, Strategic and Statistical Considerations," .Journal of Personality and Social Psychology., 51 (6), 1173-82.

Bither, Stewart W. (1972), "Effects of Distraction and Commitment on the Persuasiveness of Television Advertising," Journal of Consumer Research, 9 (February), 1-5.

Chattopadhyay Amitava and Joseph W. Alba (1988), "The Situational Importance of Recall and Inference in Consumer Decision Making," Journal of Consumer Research, 15 (June), 1-11.

and Kunal Basu (1990), "Humor in Adverstising: The Moderating Role of Prior Brand Evaluation," Journal of Marketing Research, Vol. 27 (November), 466-76.

Duncan, Calvin P. and James E. Nelson (1985), "Effects of Humor in a Radio Advertising Experiment," Journal of Advertising, 14, 33-40.

Edell, Julie A. and Richard Staelin (1983), "The Information Processing of Pictures in Print Advertisements," Journal of Consumer Research, 10 (June), 45-61.

Esslin, Martin (1969), The Theatre of the Absurd. Garden City, NY: Doubleday \& Company. Fawcett, Adrienne Ward (1995), "The Fifth Best," Advertising Age, Spring, 36-39.

Festinger, Leon and N. Maccoby (1964), "On Resistance to Persuasive Communications," Journal of Abnormal and Social Psychology, Vol. 68, 359-366. 
Gardner, David M. (1970), "The Distraction Hypothesis in Marketing," Journal of Advertising Research, 10 (December), 25-30.

Haaland, Gordon A. and M. Venkatesan (1968), "Resistance to Persuasive Communications: An Examination of Distraction Hypothesis," Journal of Personality and Social Psychology, 9 (June), 167-170.

Heckler, Susan E. and Terry L. Childers (1992), "The Role of Expectancy and Relevancy in Memory for Verbal and Visual Information: What is Incongruency?" Journal of Consumer Research, 18 (March), 475-492.

Herr, Paul M. (1989), "Priming Price: prior Knowledge and Context Effects," Journal of Consumer Research, 16 (June), 67-75.

, Steven J. Sherman, and Russell H. Fazio (1983), "On the Consequences of Priming: Assimilation and Contrast Effects," Journal of Experimental Social Psychology, 19, $323-340$.

Holbrook, Morris, and Rajeev Batra (1987), "Assessing the Role of Emotions as Mediators of Consumer Responses to Advertising," Journal of Consumer Research, 14 (December), $404-420$.

Hollander, Stephen W. and Jacob Jacoby (1973), "Recall of Crazy, Mixed-Up TV Commercials," Journal of Advertising Research, Vol. 13 (June), 39-42.

Homer, Pamela M. (1986), "Surrealism and Advertising: A Test of Alternative Explanations," unpublished Ph.D. dissertation, University of Oregon.

Houston, Michael J., Terry L. Childers, and Susan E. Heckler (1987), "Picture-Word Consistency and The Elaborative Processing of Advertisements," Journal of Marketing Research, 13 (November), 359-69.

Inman, Jeffrey J., Leigh McAlister, and Wayne D. Hoyer (1990), "Promotion Signal: Proxy for a Price-cut?," Journal of Consumer Research, 17 (June), 74-81.

Johnson, Eric J., and J. Edward Russo (1984), "Product Familiarity and Learning New Information," Journal of Consumer Research, 11 (June), 542-550.

Kanner, Bernice (1988), "Vision Quest," New York Magazine, (December 12), 16-18.

Kierkegaard, Soren (1946), "Fear and Trembling," in a Kierkegaard Anthology, ed. Robert Bretall, New York, Modern Library. 
Lutz, Kathy A. and Richard J. Lutz (1977), "Effects of Interactive Imagery on Learning: Application to Advertising," Journal of Applied Psychology, 62, 4, 493-498.

Lynch, J. and Thomas Srull (1982), "Memory and Attentional Factors in Consumer Choice: Concepts and Research Methods," Journal of Consumer Research, 9 (June), 18-37.

Messaris, Paul (1997), Visual Persuasion: The Role of Images in Advertising, Thousand Oaks: Sage Publications.

Nelson, James E., Calvin P. Duncan, and Nancy T. Frontczak (1985), "The Distraction Hypothesis and Radio Advertising," Journal of Marketing, 49 (Winter), 60-71.

O'Brien, Edward J. and Clyde R. Wolford (1982), "Effect of Delay in Testing on Retention of Plausible Versus Bizarre Mental Images," Journal of Experimental Psychology, Vol. 8, No. 2, 148-152.

Osgood, Charles E., G. J. Suci, and P. H. Tannenbaum (1957), The Measurement of Meaning. Urbana, Il: University of Illinois Press.

(1964), Method and Theory in Experimental Psychology, New York: Oxford University Press.

Osterhouse, Robert A. and Timothy C. Brock (1970), "Distraction Increases Yielding to Propaganda by Inhibiting Counterarguing," Journal of Personality and Social Psychology, 15 (4), 344-358.

Perreault, William D. and Lawrence E. Leigh (1989), "Reliability of Nominal Data Based on Qualitative Judgments," Journal of Marketing Research, Vol. 26, (May), 135-148.

Petty Richard E., Gary L. Wells, and Timothy C. Brock (1976), "Distraction Can Enhance or Reduce Yielding to Propaganda: Thought Disruption Versus Effort Justification," Journal of Personality and Social Psychology, Vol. 34, No. 5, 874-884.

and John T. Cacioppo (1981), Attitude and Persuasion: Classic and Contemporary Approaches. Iowa: Wm. C. Brown Company Publishers.

and (1985), "The Elaboration Likelihood Model of Persuasion," in Advances in Experimental Social Psychology, Vol. 19, L. Berkkowitz, ed. New York: Academic Press, Inc. 123-205.

and (1986), Communication and Persuasion: Central and Peripheral Routes to Attitude Change, New York: Springer-Verlag. 
Richter, Hans (1965), Dada Art and Anti-Art, New York: McGraw Hill.

Rossiter, John R. and Larry Percy (1978),"Visual Imaging Ability as a Mediator of Advertising Response," in Advances in Consumer Research, 5, H. Keith Hunt, ed. Ann Arbor, MI: Association for Consumer Research 621-628.

and McGraw-Hill, Inc.

(1987), Advertising and Promotion Management. New York , NY:

Stern, Barbara B. (1990), "Marketing as Drama: Theatre of the Absurd," Research in Consumer Behavior, Vol. 4, 189-209.

(1992), " Crafty Advertisers: Literary Versus Literal Deceptiveness," Journal of Public Policy \& Marketing, Vol. 11 (1) Spring, 72-81.

Sternthal, Brian, Alice M. Tybout, and Bobby J. Calder (1987), "Confirmatory Versus Comparative Approaches to Judging Theory Tests," Journal of Consumer Research, 14 (June), 114-125.

Sujan, Mita (1985), "Consumer Knowledge: Effects on Evaluation Strategies Mediating Consumer Judgments," Journal of Consumer Research, 12 (June), 31-46.

Tesser Abraham and Christopher Leone (1977), "Cognitive Schemas and Thought as Determinants of Attitude Change," Journal of Experimental Social Psychology, Vol. $13,340-356$.

Tzara, Trstan (1957), "Introduction to Georges Hugnet," L'Adventure Dada, Paris : Galerie de l'Institut. 


\section{SERIE DE DOCUMENTOS DE TRABAJO}

No 1 Chile 1973-1984: Un Caso de Política Económica, Carlos F. Cáceres, Daniel Tapia, Francisco Rosende y Ximena González. (Febrero, 1986).

№ 2 Colombia 1973-1984: Un Caso de Política Económica, Carlos F. Cáceres, Daniel Tapia, Francisco Rosende y Ricardo Rainieri. (Julio, 1986).

$N^{\circ} 3$ Argentina 1973-1984: Un Caso de Política Económica, Carlos F. Cáceres, Daniel Tapia, Francisco Rosende y Felipe González. (Septiembre, 1986).

No 4 La Pobreza según la Encuesta de Presupuestos Familiares, Alejandro Rojas y Ricardo Avello. (Abril, 1990).

No 5 Distribución Contractual: Un Estudio Empírico para Chile, Rafael Macherone. (Diciembre 1990).

No 6 Racionalidad Empresarial y Bien Común, Carlos F. Cáceres. (Diciembre, 1990).

No 7 Salarios Mínimos e Ingreso de los Asalariados, Alejandro Rojas. (Junio, 1991).

No 8 Proyecciones del Fondo de Pensiones y de sus Opciones de Inversión, Manuel Brugal K., Alvaro Feller Sch., Rafael Macherone M. y Rafael Menares G. (Julio, 1991).

No 9 Securitización: Una nueva Alternativa de Inversión para los Fondos de Pensiones, Alvaro Feller Sch. y Rafael Macherone M. (Julio, 1991).

No 10 Huelga: Enfoques Teóricos, Análisis del Caso Chileno y Evidencia Internacional, Arturo Alegría Ch. y Fernando Coloma C. (Julio, 1992).

No 11 Experiencias de Privatizaciones en Chile: Laboratorio Chile, Soquimich y Cap., Rodrigo Alonso Z. (Octubre, 1994).

No 12 Experiencias de Privatizaciones en Chile: Lan Chile, Entel y CTC., Alejandro Rojas Pinaud. (Octubre, 1994).

$\mathbf{N}^{\circ} 13$ Experiencias de Privatizaciones en Chile: Las Empresas del Sector Eléctrico, Mirencho Videla. (Octubre, 1994).

$\mathbf{N}^{\circ} 14$ Experiencias de Privatizaciones en Chile: ISE, Banco de Chile y Provida, Rafael Macherone Maino. (Octubre, 1994).

№ 15 Política Agrícola Común de la Unión Europea, Juan Ignacio Domínguez C. (Diciembre, 1996). 
$N^{\circ} 16$ Effects of Absurdity in Advertising: The Moderating Role of Product Category Attitude and the Mediating Role of Cognitive Responses, Leopoldo Arias B., Goutam Chakraborty y John C. Mowen. (Marzo, 2000). 